I

Original papers keep pouring in to the editorial office, and starting this year we are increasing the number of issues from eight to twelve per year. We are also introducing a new system of submission, a very welcome change for authors, reviewers and editors. During the upcoming year, we will make some minor changes to the reference format in order to make life easier for those who use referencing software and also in order to align to the referencing systems used in the other Nutrition Society journals.

The Out of the Box column will remain as it is, with the faithful Geoffrey Cannon writing OOTB every month, sometimes provocative and always thoughtful. We do want to see the journal getting more letters and commentaries. If you feel provoked or perhaps slightly inspired by what you read in this journal, please react, write to us!

In this particular issue you will find the normal blend of papers, covering dietary and physical activity assessment methods and surveys, interventions and project descriptions. The geographic spread is excellent; we have papers from Africa, Asia, the Middle East, Europe and North America.

As usual, all papers offer interesting reading, but one in particular, the paper by Semba, Kalm, de Pee, Ricks, Sari and Bloem from Indonesia will be mentioned here. The contribution on paternal smoking and its detrimental impact on child malnutrition in Indonesia $^{1}$ points at the importance of bringing together several aspects of a child's environment in order to promote nutritional health on his/her behalf. Tobacco poses a major threat to the smoker and the passive smoker as well as to the unborn child. This paper shows the impact of tobacco addiction on household economy, which leads to detrimental effects on the young and defenceless child. The tobacco companies' efforts to market their products in developing countries must certainly be fought - not only by the antitobacco lobby, but also by those of us actively working to promote children's nutritional health - in a more holistic perspective looking at all effects of tobacco use ${ }^{2-4}$ during pregnancy, lactation and onwards.

\section{Agneta Yngve}

Editor-in-Chief

\section{References}

1 Semba RK, Kalm LM, de Pee S, Ricks MO, Sari M, Bloem MW. Paternal smoking is associated with increased risk of child malnutrition among poor urban families in Indonesia. Public Health Nutrition 2007; 10(1): 7-15.

2 Esamai FO. Relationship between exposure to tobacco smoke and bronchial asthma in children: a review. East African Medical Journal 1998; 75(1): 47-50.

3 Feinson JA, Chidekel AS. Adult smoking and environmental tobacco smoke: a persistent health threat to children. Delaware Medical Journal 2006; 78(6): 213-8.

4 McCaffree MA, Boyer J. Women and children: tobacco or health. Journal of the Oklahoma State Medical Association 2002; 95(3): 167-9. 